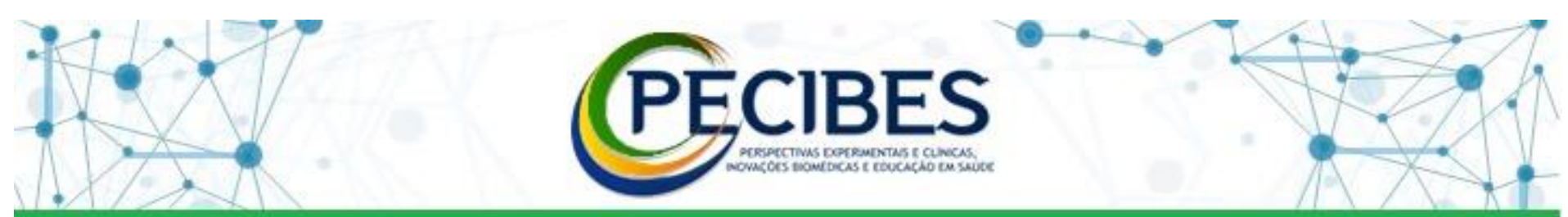

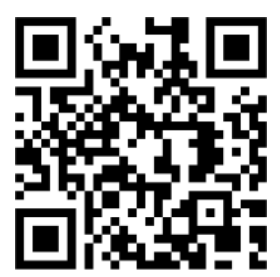

http://www.seer.ufms.br/in dex.php/pecibes/index

* Autor correspondente: Milena Dalariva Amorim,

Universidade Federal de Mato Grosso do Sul UFMS.Email:milena_da lariva@hotmail.com

Descritores: Serviços de Assistência Domiciliar. Atenção Primária à Saúde. Sistema Único de Saúde. Continuidade da Assistência ao Paciente. Integralidade em Saúde.

Key-words: Home Care Services. Primary Health Care. Unified Health System. Continuity of Patient Care. Integrality in Health.

Descriptores: Servicios de Atención de Salud a Domicilio. Atención Primaria de Salud. Sistema Único de Salud. Continuidad de la Atención al Paciente. Integralidad en Salud.

\section{Acompanhamento de pacientes em área descoberta pelo Serviço de Atenção Domiciliar}

\author{
Monitoring of patients in an uncovered area of the Home Care Service
}

Milena Dalariva Amorim ${ }^{1}$, Daniela Miyuki Sato ${ }^{1}$, Joice Lourenço da Silva ${ }^{2}$, Elen Ferraz Teston ${ }^{3}$

1. Graduanda em Enfermagem. Universidade Federal de Mato Grosso do Sul. Campo Grande, Mato Grosso do Sul, Brasil.

2. Enfermeira.Programa de Pós-Graduação em Enfermagem da Universidade Estadual de Maringá. Maringá, Paraná, Brasil.

3. Enfermeira. Doutora. Departamento de Enfermagem da Universidade Federal de Mato Grosso do Sul. Campo Grande, Mato Grosso do Sul, Brasil.

Introdução: o Serviço de Atenção Domiciliar (SAD), regido pela Portaria $n^{\circ} 825 / 2016$, organiza-se a partir de uma base territorial também denominada região de saúde, e constitui um dos pontos da Rede de Atenção à Saúde (RAS). Contudo, nem todo território possui cobertura das ações oferecidas pelo SAD o que necessita do envolvimento de outros pontos da RAS. Objetivo: descrever como ocorre o cuidado à pacientes que residem em área descoberta pelas equipes do SAD. Material e métodos: pesquisa descritiva-exploratória, qualitativa, realizada com profissionais do SAD de uma capital do centro-oeste brasileiro. Os dados foram coletados nos meses de agosto a outubro de 2019, por meio de entrevistas semiestruturadas e submetidas à análise de conteúdo proposta por Bardin. Estudo aprovado pelo Comitê de Ética sob parecer $n^{\circ}$ 3.226.138. Resultados: participaram sete profissionais. Eles referiram que para o acesso e continuidade das ações de cuidado pelos pacientes e suas famílias residentes em regiões descobertas pelo serviço, orientam a busca pelo atendimento nos demais pontos da RAS. O contato telefônico e a visita domiciliar são realizados para reconhecimento do paciente e seu contexto familiar, seguidos pelo acionamento da região de saúde para verificação da disponibilidade de atendimento pelos profissionais do Núcleo Ampliado de Saúde da Família (NASF). A ausência de uma unidade de saúde da família que atenda a área de moradia do paciente foi elencada como dificuldade para o direcionamento e manutenção da assistência. Conclusões: o fluxo dos pacientes residentes fora da área de abrangência do SAD perpassa burocracias relacionadas à organização da rede. Entretanto, constata-se que as equipes deste serviço tentam articular suas ações com vistas ao reconhecimento pela RAS e a consequente oferta de uma assistência integral e contínua às famílias. 